\title{
Article \\ Population Pharmacokinetic Modeling and Dose Optimization of Vancomycin in Chinese Patients with Augmented Renal Clearance
}

\author{
Sixuan Zhao ${ }^{1}\left(\mathrm{Na} \mathrm{He}^{1,2}\right.$, Yahui Zhang ${ }^{1,2}$, Chuhui Wang ${ }^{1,2}{ }^{\oplus}$, Suodi Zhai ${ }^{1,2, *}$ and Chao Zhang ${ }^{3, *}$ \\ 1 Department of Pharmacy, Peking University Third Hospital, Beijing 100191, China; \\ zhao_sixuan@126.com (S.Z.); hn12141122@163.com (N.H.); zhangyahui61@126.com (Y.Z.); \\ chuhui_wang@163.com (C.W.) \\ 2 Department of Pharmacy Administration and Clinical Pharmacy, School of Pharmaceutical Science, \\ Peking University, Beijing 100191, China \\ 3 Department of Pharmacy, Beijing Tongren Hospital, Capital Medical University, Beijing 100730, China \\ * Correspondence: zhaisuodi@163.com (S.Z.); laural.zhang@yahoo.com (C.Z.); Tel.: +86-(010)-8226-6686 (S.Z.); \\ +86-(010)-5826-8176 (C.Z.)
}

check for

updates

Citation: Zhao, S.; He, N.; Zhang, Y.; Wang, C.; Zhai, S.; Zhang, C.

Population Pharmacokinetic

Modeling and Dose Optimization of

Vancomycin in Chinese Patients with Augmented Renal Clearance.

Antibiotics 2021, 10, 1238. https://

doi.org/10.3390/antibiotics10101238

Academic Editors: Antonello Di

Paolo and Albert Figueras

Received: 28 August 2021

Accepted: 8 October 2021

Published: 12 October 2021

Publisher's Note: MDPI stays neutral with regard to jurisdictional claims in published maps and institutional affiliations.

Copyright: (C) 2021 by the authors. Licensee MDPI, Basel, Switzerland. This article is an open access article distributed under the terms and conditions of the Creative Commons Attribution (CC BY) license (https:/ / creativecommons.org/licenses/by/ $4.0 /)$.

\begin{abstract}
Patients with augmented renal clearance (ARC) have been described as having low vancomycin concentration. However, the pharmacokinetic model that best describes vancomycin in patients with ARC has not been clarified. The purpose of this study is to determine the pharmacokinetic of vancomycin in Chinese adults and the recommend dosage for patients with different renal function, including patients with ARC. We retrospectively collected 424 vancomycin serum concentrations from 209 Chinese patients and performed a population pharmacokinetic model using NONMEM 7.4.4. The final model indicated that the clearance rate of vancomycin increased together with the creatinine clearance, and exhibited a nearly saturated curve at higher creatinine clearance. The estimated clearance of vancomycin was between 3.46 and $5.58 \mathrm{~L} / \mathrm{h}$ in patients with ARC, with 5.58 being the maximum theoretical value. The central volume of distribution increased by more than three times in patients admitted to Intensive Care Unit. Monte Carlo simulations were conducted to explore the probability of reaching the target therapeutic range (24-h area under the curve: $400-650 \mathrm{mg} \cdot \mathrm{h} / \mathrm{L}$, trough concentration: 10-20 mg/L) when various dose regimens were administered. The simulations indicated that dose should increase together with the creatinine clearance until $180 \mathrm{~mL} / \mathrm{min}$. These findings may contribute to improving the efficacy and safety of vancomycin in patients with ARC.
\end{abstract}

Keywords: area under the curve; augmented renal clearance; dosage regimens; population pharmacokinetic model; vancomycin

\section{Introduction}

Vancomycin is a glycopeptide antibiotic used to treat a number of gram-positive infections [1]. It is the first-line choice of treatment for infections caused by methicillinresistant Staphylococcus aureus (MRSA).

Vancomycin is excreted in urine by glomerular filtration, without appreciable metabolism [2]. The clearance rate is mainly affected by renal function. Dosage must be adjusted for patients with renal dysfunction because the risk of toxicity is increased by high blood concentrations [3]. At the same time, patients with augmented renal clearance (ARC) have lower concentrations of vancomycin, leading to suboptimal drug exposure and treatment failure $[4,5]$. A longer length of stay in the Intensive Care Unit has also been reported [6,7]. Of note, the administration of subtherapeutic doses increased the prevalence of antibiotic resistance [8].

Individualized dosage regimen is therefore necessary for safe and effective administration. Establishing a population pharmacokinetic model is optimal for planning dosing 
regimen. However, most of the studies provided only regimens for patients with impaired renal function [9-12]. The pharmacokinetic profile of vancomycin in patients with ARC has not been well established and an appropriate dosing recommendation is very necessary.

We therefore conducted a population pharmacokinetic study of vancomycin to estimate its variability in patients with abnormal renal function, including patients with ARC.

\section{Results}

\subsection{Patients and Data Collection}

We retrospectively collected and analyzed 424 vancomycin serum concentrations from 209 Chinese patients. Among these, 82 (39.2\%) were admitted at the Intensive Care Unit (ICU) and $127(60.8 \%)$ were admitted at other departments. A total of 40 $(48.8 \%)$ ICU patients and $6(2.9 \%)$ non-ICU patients developed shock or evidence of multiple organ failure. $51(24.4 \%)$ patients had a creatinine clearance $\left(\mathrm{CL}_{\mathrm{cr}}\right) \geq 130 \mathrm{~mL} / \mathrm{min}$. Vancomycin was administered at different dosages (median daily dosage $1875 \mathrm{mg}$ ), and mostly evaluated between 5 and $12 \mathrm{~h}$ after administration. Clinical characteristics of enrolled patients are displayed in Table 1.

Table 1. Demographic characteristics of patients.

\begin{tabular}{|c|c|}
\hline Characteristic & Patients $(\mathrm{N}=209)$ \\
\hline Male, n (\%) & $126(60.3 \%)$ \\
\hline ICU, n $(\%)$ & $82(39.2 \%)$ \\
\hline $\mathrm{CL}_{\mathrm{cr}} \geq 130 \mathrm{~mL} / \mathrm{min}, \mathrm{n}(\%)$ & $51(24.4 \%)$ \\
\hline Shock, n (\%) & $39(18.7 \%)$ \\
\hline MOF, $\mathrm{n}(\%)$ & $7(3.3 \%)$ \\
\hline Age, years (mean $\pm S D)$ & $66.0 \pm 16.4$ \\
\hline TBW, $\mathrm{kg}($ mean $\pm \mathrm{SD})$ & $63.4 \pm 12.9$ \\
\hline Mean $\mathrm{CL}_{\mathrm{cr}}{ }^{\mathrm{a}}, \mathrm{mL} / \mathrm{min}$ (median (range)) & $86.7(18.4-390.7)$ \\
\hline Number of samples, $\mathrm{n}$ & 424 \\
\hline \multicolumn{2}{|l|}{ Number of samples per patient, $\mathrm{n}(\%)$} \\
\hline 1 & $103(49.3 \%)$ \\
\hline 2 & $50(23.9 \%)$ \\
\hline 3 & $29(13.9 \%)$ \\
\hline$\geq 4$ & $27(12.9 \%)$ \\
\hline Mean daily dosage, mg (median (IQR)) & $1875.0(1461.9-2352.0)$ \\
\hline \multicolumn{2}{|c|}{ Number of samples collected after the start of infusion, $\mathrm{n}(\%)$} \\
\hline$<3 \mathrm{~h}$ & $25(5.9 \%)$ \\
\hline $3-5 h$ & $16(3.8 \%)$ \\
\hline $5-12 \mathrm{~h}$ & $294(69.3 \%)$ \\
\hline $12-24 \mathrm{~h}$ & $75(17.7 \%)$ \\
\hline$>24 \mathrm{~h}$ & $14(3.3 \%)$ \\
\hline \multicolumn{2}{|l|}{ Mean concentration after the start of infusion, $\mathrm{mg} / \mathrm{L}$} \\
\hline$<3 \mathrm{~h}$ & 29.5 \\
\hline $3-5 \mathrm{~h}$ & 22.9 \\
\hline $5-12 \mathrm{~h}$ & 16.5 \\
\hline $12-24 \mathrm{~h}$ & 15.3 \\
\hline$>24 \mathrm{~h}$ & 10.3 \\
\hline
\end{tabular}

$\overline{\mathrm{ICU}}$, Intensive Care Unit; $\mathrm{CL}_{\mathrm{cr}}$, creatinine clearance calculated by the Cockcroft-Gault equation; MOF, multiple organ failure; SD, standard deviation; TBW, total body weight; IQR, interquartile range; ${ }^{a}$, the mean value of $\mathrm{CL}_{\mathrm{cr}}$ for each patient during admission.

\subsection{Population Modeling}

According to the goodness-of-fit (GOF) plots and Akaike information criterion (AIC) values, a two-compartment model (AIC, 2089.498) was more appropriate to describe the pharmacokinetic profile than a one-compartment model (AIC, 2162.859). The interindividual variability (IIV) was successfully estimated for clearance (CL) and central volume of distribution $\left(\mathrm{V}_{\mathrm{c}}\right)$. The $\mathrm{CL}_{\mathrm{cr}}$ and the admission at the ICU were identified as significant covariates for $\mathrm{CL}$ and $\mathrm{V}_{\mathrm{c}}$, respectively, in the forward addition and back- 
ward elimination procedures. The final model was therefore developed to describe the concentration-time profile of vancomycin (Equations (1)-(4)):

$$
\begin{gathered}
\mathrm{CL}=\frac{5.58 * \mathrm{CG}_{\mathrm{i}}^{1.5}}{\left(93.8^{1.5}+\mathrm{CG}_{\mathrm{i}}{ }^{1.5}\right)} * \mathrm{e}^{\mathfrak{\eta}_{1}}(\mathrm{~L} / \mathrm{h}), \\
\mathrm{V}_{\mathrm{c}}=8.02(\text { non }-\mathrm{ICU} \text { patients }) \text { or } 35.7(\mathrm{ICU} \text { patients }) * \mathrm{e}^{\mathfrak{\eta}_{2}}(\mathrm{~L}), \\
\mathrm{Q}=2.66(\mathrm{~L} / \mathrm{h}), \\
\mathrm{V}_{\mathrm{p}}=36.8(\mathrm{~L}),
\end{gathered}
$$

where CG is the creatinine clearance estimated by Cockcroft-Gault equation, while 5.58 is the theoretical maximum clearance of vancomycin in patients with creatinine clearance between 18.4 and $390.7 \mathrm{~mL} / \mathrm{min}$. When the creatinine clearance is $93.8 \mathrm{~mL} / \mathrm{min}$, the drug clearance is at $50 \%$ of its maximum value. The steepness parameter is 1.5 . $\mathrm{V}_{\mathrm{c}}$ is $8.02 \mathrm{~L}$ and 35.7 L for non-ICU and ICU patients, respectively. The typical value of the peripheral volume of distribution $\left(V_{p}\right)$ is 36.8 L. $\eta_{1}$ and $\eta_{2}$ represent the interindividual variations of $\mathrm{CL}$ and $\mathrm{V}_{\mathrm{c}}$, respectively.

\subsection{Model Evaluation}

The GOF plots indicate that the final model predictions agreed with the observed plasma concentration of vancomycin. Observed data versus either the population or the individual predicted values were closely distributed around the $\mathrm{y}=\mathrm{x}$ line (Figure $1 \mathrm{a}, \mathrm{b}$ ). The conditional weighted residuals (CWRES) were approximately 0 , randomly and homogeneously distributed (Figure 1c,d). A success rate of $84.6 \%$ was obtained from the bootstrap analysis. The estimated model parameters were within the bootstrap confidence

\begin{tabular}{|c|c|c|c|}
\hline Parameter & $\begin{array}{c}\text { Base Model Estimate } \\
\text { (RSE\%) }\end{array}$ & $\begin{array}{c}\text { Final Model } \\
\text { Estimate (RSE\%) }\end{array}$ & $\begin{array}{c}\text { Bootstrap Median } \\
(95 \% \mathrm{CI})\end{array}$ \\
\hline CL (L/h) & $2.56(7 \%)$ & - & - \\
\hline $\mathrm{CL}_{\max }(\mathrm{L} / \mathrm{h})$ & - & $5.58(17 \%)$ & $5.58(4.26-8.52)$ \\
\hline $\mathrm{CG}_{\text {CLmax50 }}(\mathrm{L} / \mathrm{h})$ & - & $93.8(24 \%)$ & 94.65 (66.99-178.63) \\
\hline $\mathrm{s}$ & - & $1.5(14 \%)$ & $1.49(1.16-1.95)$ \\
\hline $\mathrm{V}_{\mathrm{c}}(\mathrm{L})$ & $13.1(11 \%)$ & - & - \\
\hline $\mathrm{V}_{\mathrm{C} \text { non-ICU }}(\mathrm{L})$ & - & $8.02(12 \%)$ & $7.90(4.90-11.80)$ \\
\hline $\mathrm{V}_{\mathrm{C} I C U}(\mathrm{~L})$ & - & $35.7(13 \%)$ & $36.66(26.68-48.37)$ \\
\hline $\mathrm{Q}(\mathrm{L} / \mathrm{h})$ & $4.9(26 \%)$ & $2.66(12 \%)$ & $2.64(1.80-3.58)$ \\
\hline $\mathrm{V}_{\mathrm{p}}(\mathrm{L})$ & $40.2(13 \%)$ & $36.8(15 \%)$ & $36.26(25.51-49.36)$ \\
\hline IIV CL & $0.319(12 \%)$ & $0.0771(16 \%)$ & $0.075(0.05-0.10)$ \\
\hline IIV $V_{c}$ & $1.65(39 \%)$ & $0.223(56 \%)$ & $0.20(0.0039-0.53)$ \\
\hline Additive residual error & $0.0479(18 \%)$ & $0.0466(14 \%)$ & $0.045(0.032-0.060)$ \\
\hline
\end{tabular}
interval (Table 2). The pc-VPC plot suggested that the simulated models were consistent with the observed values (Figure 2).

Table 2. Population parameter estimates of the base and final population models.

CL, clearance; $\mathrm{CL}_{\max }$, theoretical maximum clearance; $\mathrm{CG}_{\mathrm{CLmax} 50}$, value of creatinine clearance reaching $50 \%$ of the maximum drug clearance; $\mathrm{s}$, steepness parameter; $\mathrm{V}_{\mathrm{C}}$, distribution volume of the central compartment; $\mathrm{V}_{\mathrm{c}}$ non-ICU, $\mathrm{V}_{\mathrm{c}}$ of non-ICU patients; $\mathrm{V}_{\mathrm{c}}$ ICU, $\mathrm{V}_{\mathrm{c}}$ of ICU patients; $\mathrm{Q}$, inter-compartment clearance; $\mathrm{V}_{\mathrm{p}}$, distribution volume of the peripheral compartment; IIV, inter-individual variability; RSE, relative standard error; CI, confidence interval. 


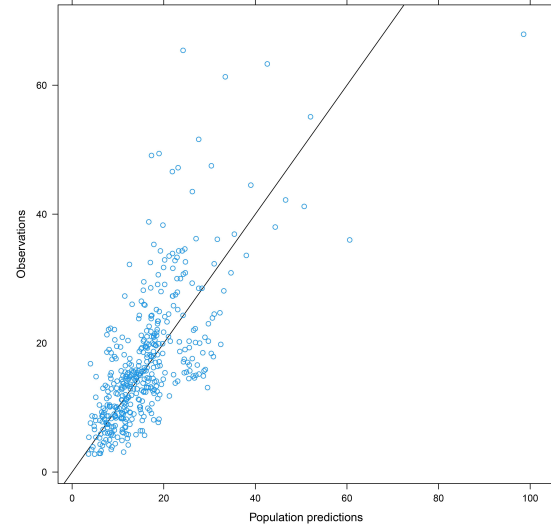

(a)

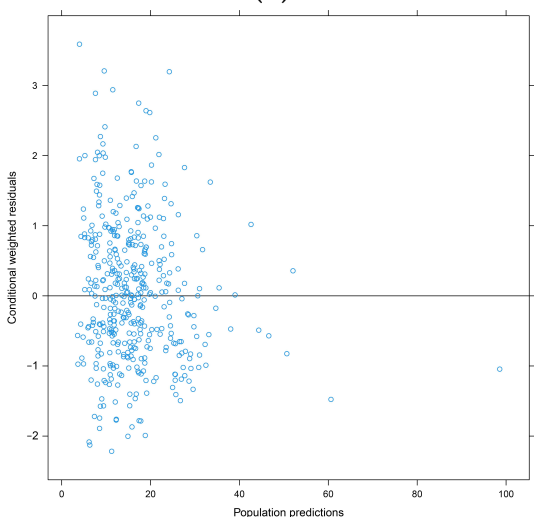

(c)

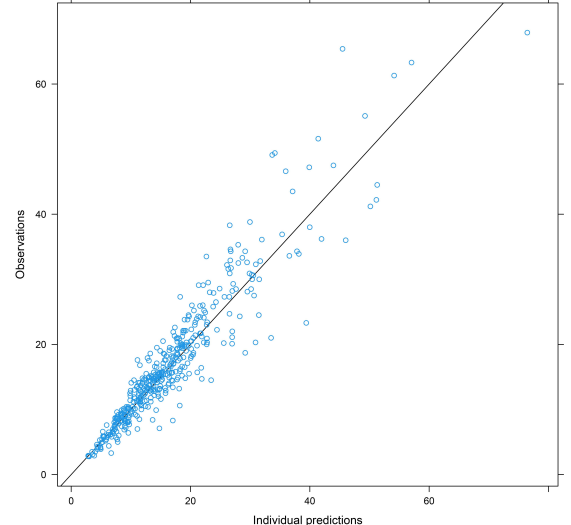

(b)

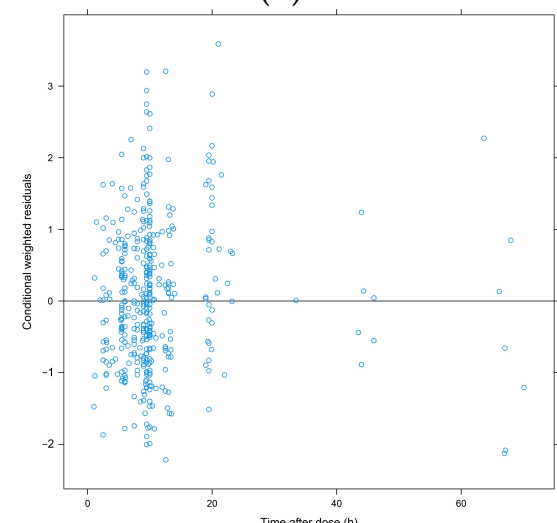

(d)

Figure 1. Goodness-of-fit plots of vancomycin population pharmacokinetic model. (a) observed concentration versus population prediction (PRED); (b) observed concentration versus individual prediction (IPRED); (c) conditional weighted residuals (CWRES) versus PRED; (d) CWRES versus time after dose (TAD).

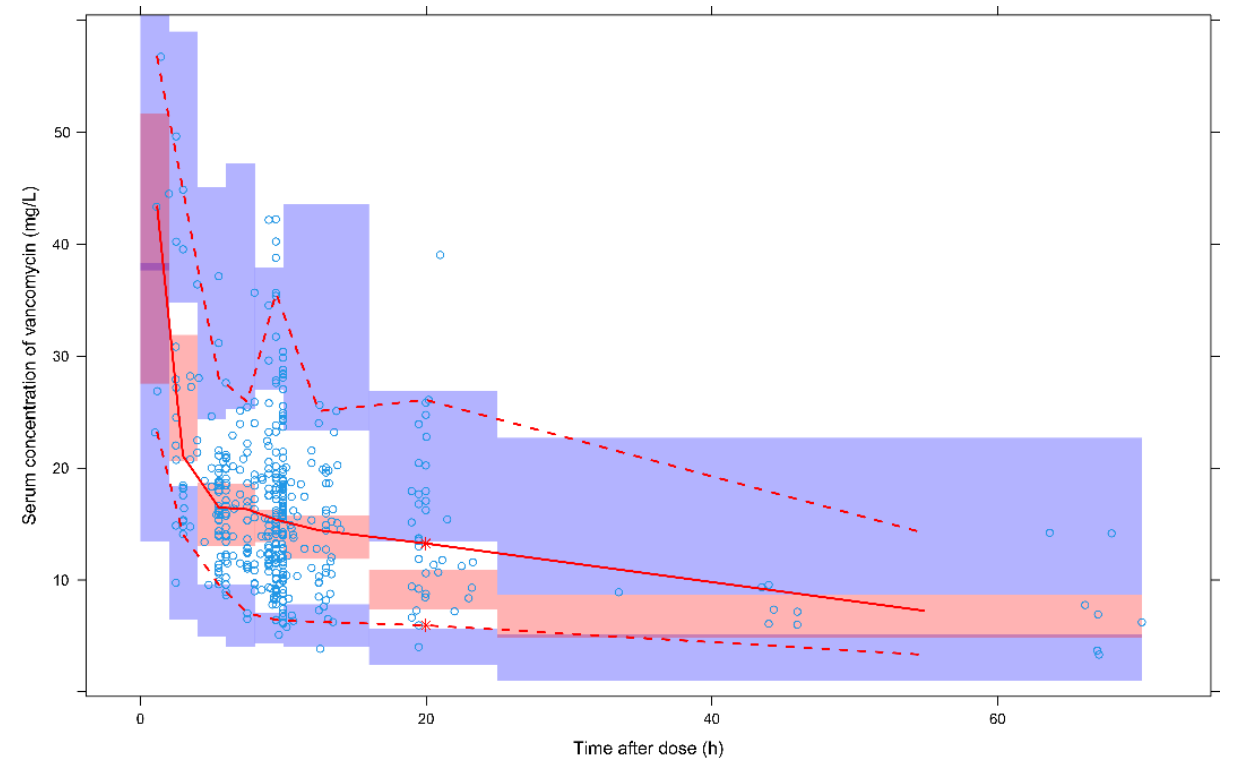

Figure 2. Prediction corrected-visual predictive check (pc-VPC) plot of the final model. Blue circles: observed vancomycin concentrations. Red solid and dashed lines: the 50th, 5th, and 95th percentiles of the observed concentrations. 3 shaded areas: the $90 \%$ CIs of the 5 th, 50 th, and 95 th percentiles of the simulated concentrations. 


\subsection{Dosage Recommendation}

The probability of $\mathrm{AUC}_{24}$ between 400 and $650 \mathrm{mg} \cdot \mathrm{h} / \mathrm{L}$ at several regimens was calculated using the final model (Figure S1). The dosage regimen providing the highest target attainment rate determined the optimal regimen. The estimated $\mathrm{AUC}_{24}$ at our regimen was shown in violin plot (Figure S2). The dose of vancomycin increased together with $\mathrm{CL}_{\mathrm{cr}}$ until $180 \mathrm{~mL} / \mathrm{min}$. The recommended dosage regimens for targeted $\mathrm{AUC}_{24}$ were summarized in Table 3 . The recommended regimens for targeted $C_{t}$ are described in Supplement Table S1. The probability of target attainment (PTA) was between 41 and $67 \%$ in patients with different renal function.

Table 3. Recommended initial dosage regimens for targeted $\mathrm{AUC}_{24}$ between 400 and $650 \mathrm{mg} \cdot \mathrm{h} / \mathrm{L}$.

\begin{tabular}{ccc}
\hline $\mathbf{C L}_{\mathbf{c r}}(\mathbf{m L} / \mathbf{m i n})$ & Dosage & PTA (\%) \\
\hline $15-29$ & $250 \mathrm{mg} \mathrm{Q} 24 \mathrm{~h}$ & 41.44 \\
$30-44$ & $500 \mathrm{mg} \mathrm{Q} 24 \mathrm{~h}$ & 53.69 \\
$45-59$ & $750 \mathrm{mg} \mathrm{Q} 24 \mathrm{~h}$ & 57.64 \\
$60-89$ & $1250 \mathrm{mg} \mathrm{Q} 24 \mathrm{~h}$ & 57.32 \\
$90-119$ & $750 \mathrm{mg} \mathrm{Q} 12 \mathrm{~h}$ & 61.58 \\
$120-149$ & $1750 \mathrm{mg} \mathrm{Q} 24 \mathrm{~h}$ & 62.33 \\
$150-179$ & $1000 \mathrm{mg} \mathrm{Q} 12 \mathrm{~h}$ & 62.56 \\
$\geq 180$ & $750 \mathrm{mg}$ Q8 h & 61.69
\end{tabular}

$\overline{\mathrm{CL}}_{\mathrm{cr}}$, creatinine clearance; PTA, probability of steady-state $\mathrm{AUC}_{24}$ between 400 and $650 \mathrm{mg} \cdot \mathrm{h} / \mathrm{L}$.

\section{Discussion}

Our results suggest that the $\mathrm{CL}_{\mathrm{cr}}$ and ICU admissions influence the pharmacokinetics of vancomycin. Patients with $\mathrm{ARC}\left(\mathrm{CL}_{\mathrm{cr}} \geq 130 \mathrm{~mL} / \mathrm{min}\right)$ showed between 1.3 and 2.1 times higher drug clearance than patients with normal kidney function. The central volume of distribution increased by 3.5 times in ICU patients, compared with non-ICU patients. We therefore designed an individualized dosing regimen based on these two covariates.

We identified the $\mathrm{CL}_{\mathrm{cr}}$ calculated with the Cockcroft-Gault equation as the most significant covariate that affected the elimination of vancomycin. The drug clearance rate increased together with $\mathrm{CL}_{\mathrm{cr}}$ in a saturation curve, with the theoretical maximum clearance being $5.58 \mathrm{~L} / \mathrm{h}$. In previous pharmacokinetic studies, the clearance rate constantly increased [13-15], whereas Chu et al. found that the trend is weaker in patients with ARC [16]. Consistently, a similar trend was plotted into a scatter diagram format with $\mathrm{CL}_{\mathrm{cr}}$ and the clearance (Supplement Figure S3). We therefore tried to fit a saturation correlation and found lower objective function value (OFV) of the model (OFV 1843.222) compared with linear (OFV 1864.24), exponential (OFV 1929.264) and power (OFV 1856.897) models, indicating that the correlation was more consistent with the actual relationship.

Although different models have been implemented regarding vancomycin pharmacokinetics, little is known about the behavior in patients with ARC [17]. In observational cohort studies, a lower blood concentration has been described in patients with ARC [18,19]. Our model suggested between 1.3 and 2.1 times higher clearance in patients with ARC than in patients with normal kidney function. Another study reported a clearance rate of $8.52 \mathrm{~L} / \mathrm{h}$, much higher than what we observed [20]. The age was used as a covariate and might explain their findings, obtained in a younger population.

The apparent volume of distribution increased by more than three times in ICU patients (35.7 L), compared with non-ICU patients (8.02 L). Previous studies reported similar results [21-23]. Several pathophysiological changes might be related to PK modifications in ICU patients [24]. Intravenous fluid loading, hypoalbuminemia and endothelial damage may increase capillary permeability and contribute to interstitial space expansion in the critically ill, especially in cases of sepsis and septic shock [25]. Hydrophilic drugs, characterized by a distribution limited to the extracellular space, are significantly affected [24]. A recent study suggested that an increased volume of distribution $\left(\mathrm{V}_{\mathrm{d}}\right)$ may be due to sepsis-induced third space losses [26]. In accordance, we found that more ICU patients 
received a diagnosis of shock or multiple organ failure. Although the two diagnoses were not identified as significant covariates of $V_{d}$ in our study, we cannot refuse the influence of these diseases on $\mathrm{V}_{\mathrm{d}}$. The proportion of patients with corresponding diagnosis is relatively low, which may interfere with the identification of influencing covariates. On the other hand, although not been diagnosed, ICU patients with different degrees of sepsis (sepsis, severe sepsis and septic shock) are associated with varying degrees of fluid retention.

A larger $V_{d}$ of hydrophilic drugs has been reported in ICU patients, but the clinical relevance is questionable. An aminoglycoside is supposed to have lower concentrations in patients with higher $V_{d}$ and therefore needs an augmented dose [24,25]. An increased dosing is also necessary for $\beta$-lactam antibiotics to prevent visible growth of a microorganism $[27,28]$. However, an increased $V_{d}$ may not have a significant effect on the maintenance dose of vancomycin, as the AUC depends only on the clearance rate at the steady state. At the same time, the increased $V_{d}$ might improve the penetration of the drug, which is helpful against certain infections. Higher loading and daily doses were suggested by some authors [29]. An augmented loading dose may increase the body's exposure to vancomycin in the initial treatment phase and may be helpful for the early elimination of the bacterium in vivo.

We recommend a dosage regimen for patients with a $\mathrm{CL}_{\mathrm{cr}}$ between 15 and $180 \mathrm{~mL} / \mathrm{min}$. Patients with a $\mathrm{CL}_{\mathrm{cr}}>180 \mathrm{~mL} / \mathrm{min}$ do not need to increase the dose, which is consistent with the saturation correlation dimension of our model. Other studies reported higher daily doses than ours $[9,12,30]$. Differences in the choice of simulation target might be the reason. The daily dose was higher when the trough concentration was used as the simulation target (Supplement Table S1). However, the AUC is more recommended as may reduce the occurrence of vancomycin-associated acute kidney injury [31,32]. A meta-analysis demonstrated that $\mathrm{AUC} /$ minimum inhibitory concentration $=400$ is a reasonable target of mortality and infection treatment failure [33]. An $\mathrm{AUC}_{24}>650 \mathrm{mg} \cdot \mathrm{h} / \mathrm{L}$ was associated with a higher risk of nephrotoxicity [34]. We therefore selected $\mathrm{AUC}_{24}$ between 400 and $650 \mathrm{mg} \cdot \mathrm{h} / \mathrm{L}$ as the target in this study [35].

Our study has some limitations. First, the sample size was limited. Other clinical data could help to characterize the differences between ICU and non-ICU patients, including the covariate Acute Physiology and Chronic Health Evaluation II or other scores. In the future, prospective studies with a larger sample size may be helpful to verify the performance of the model, as well as the effectiveness of the proposed regimens in real-world patients.

\section{Materials and Methods}

\subsection{Patients and Data Collection}

This study was approved by Peking University Third Hospital (PUTH) Ethics Committee (reference number M2020377). Data from hospitalized patients at PUTH between January 2010 and June 2018 were retrospectively collected. Age, gender, total body weight (TBW), department, primary diagnosis, vancomycin dosage, serum creatinine ( $\mathrm{SCr}$ ) and serum vancomycin concentration were recorded. Patients were eligible to participate in the study if they: (i) aged $\geq 18$ years; (ii) received intermittent intravenous vancomycin therapy; (iii) had data recorded, including age, gender, TBW, $\mathrm{SCr}$ and at least one serum vancomycin measurement. Patients were excluded from the study if they: (i) had been diagnosed with end-stage renal disease, including patients with $\mathrm{CL}_{\mathrm{cr}}<15 \mathrm{~mL} / \mathrm{min}$ or receiving renal replacement therapy; (ii) had been diagnosed with acute kidney injury before or during treatment; (iii) had been admitted to the Hematology Department or the Surgical Department of the Intensive Care Unit; (iv) had been pre-treated with vancomycin in other hospitals; (v) had significant missing data.

\subsection{Evaluation of Serum Vancomycin Concentration}

Vancomycin hydrochloride (abbreviated as vancomycin) for intravenous administration was obtained from Eli Lilly and Company and Zhejiang Pharmaceutical Co., Ltd. The serum concentration of vancomycin was determined by commercial chemilumines- 
cent microparticle immunoassay (CMIA) assay using the ARCHITECT platform with the ARCHITECT iVancomycin assay obtained from Abbott Laboratories Trading Co., Ltd. (Shanghai, China).

\subsection{Population Pharmacokinetic Modeling}

The model estimation was performed using NONMEM 7 software (version VII, level 4.4; ICON Development Solutions, Ellicott City, MD, USA) with the FOCEI method. Analysis and post-processing were performed with the PsN toolkit and Xpose4 (version 4.6.1) through the statistical package $\mathrm{R}$.

Classical one- and two-compartment models were fitted to the data. An exponential model was used to estimate the interindividual variability of the pharmacokinetic parameters (Equation (5)). The residual errors were described by a constant coefficient of variation model (Equation (6)). AIC values, GOF plots and the numerical estimates were used to determine the structure model.

$$
\mathrm{P}_{\mathrm{i}}=\mathrm{P}_{\text {pop }} * \mathrm{e}^{\eta} \text {, }
$$

where $P_{\text {pop }}$ and $P_{i}$ represent the pharmacokinetic parameters for the population and each individual, respectively. $\eta$ is a random variable for each individual following a normal distribution with a mean of 0 and a variance of $\omega^{2}$.

$$
\mathrm{C}_{\text {obs }}=\mathrm{C}_{\text {pred }}+\mathrm{C}_{\text {pred }} * \varepsilon,
$$

where $C_{\text {pred }}$ and $C_{\text {obs }}$ represent the predicted concentration and the observed vancomycin concentration in the serum, respectively. $\varepsilon$ represents the proportional error assumed to follow a normal distribution with a mean of 0 and a variance of $\sigma^{2}$.

Factors considered in relation to the pharmacokinetics of vancomycin were age, gender, TBW, department, primary diagnosis and $\mathrm{CL}_{\mathrm{cr}}$ estimated according to the Cockcroft-Gault equation. An exploratory graphical analysis was performed to identify characteristics that may influence pharmacokinetic parameters. The covariates showing a correlation with pharmacokinetic parameters were introduced into the model sequentially. The significance of the covariates was calculated through the OFV. An OFV decrease of more than 3.84 $(p<0.05)$ was considered statistically significant during the forward inclusion process. All of the significant covariates were incorporated in the full model and then excluded from the model one at a time. An OFV increase of more than 10.83 from the full model $(p<0.001)$ was considered statistically significant.

\subsection{Model Validation}

Validation was performed by GOF plots, bootstrap and prediction corrected-visual predictive check (pc-VPC) approaches. GOF plots illustrated the overall performance of the model. The bootstrap median values and 95\% confidence intervals for each estimate were compared with those from the original dataset. The pc-VPC approach was applied to determine whether sample data were consistent with the $90 \%$ prediction interval of 1000 simulated datasets from the final model.

\subsection{Simulation and Dose Optimization}

The Monte Carlo simulations $(\mathrm{N}=10,000)$ were performed for each renal function classification (i.e., $15-29 \mathrm{~mL} / \mathrm{min}, 30-44 \mathrm{~mL} / \mathrm{min}, 45-59 \mathrm{~mL} / \mathrm{min}, 60-89 \mathrm{~mL} / \mathrm{min}$, 90-119 mL/min, 120-149 mL/min, 150-179 mL/min, 180-209 mL/min, 210-239 mL/min, 240-269 mL/min, and 270-299 mL/min). Dosing intervals were set at 8, 12 or $24 \mathrm{~h}$ with 250-2500 mg per dose. The probability of target (steady state $24-\mathrm{h}$ area under the curve $\left(\mathrm{AUC}_{24}\right): 400-650 \mathrm{mg} \cdot \mathrm{h} / \mathrm{L}$, steady state trough concentration $\left.(\mathrm{Ct}): 10-20 \mathrm{mg} / \mathrm{L}\right)$ attainment was calculated. The dosage regimens with the highest PTA were recommended. 


\section{Conclusions}

The current study established a population pharmacokinetic model for vancomycin in adult patients with different renal function, including patients with ARC. An initial dosing regimen of vancomycin was proposed for patients with insufficient, normal and augmented renal clearance.

Supplementary Materials: The following are available online at https:/ /www.mdpi.com/article/10 .3390/antibiotics10101238/s1, Figure S1: Probability attainment for targeted AUC 24 400-650 mg.h/L., Figure S2. Distribution of $\mathrm{AUC}_{24}$ at recommended vancomycin regimens., Figure S3. Scatter diagram format with creatinine clearance calculated by the Cockcroft-Gault equation (CG) and the drug clearance (Clearance)., Table S1: Recommended initial dosage regimens for targeted trough concentration of $10-20 \mathrm{mg} / \mathrm{L}$ attainment.

Author Contributions: Conceptualization, S.Z. (Suodi Zhai), C.Z. and S.Z. (Sixuan Zhao); methodology, S.Z. (Sixuan Zhao); validation, Y.Z., C.W. and S.Z. (Sixuan Zhao); formal analysis, S.Z. (Sixuan Zhao); data curation, S.Z. (Sixuan Zhao) and N.H.; writing-original draft preparation, S.Z. (Sixuan Zhao); writing-review and editing, C.Z. and N.H. All authors have read and agreed to the published version of the manuscript.

Funding: This research received no external funding.

Institutional Review Board Statement: The study was conducted according to the guidelines of the Declaration of Helsinki, and approved by the Ethics Committee of Peking University Third Hospital (protocol code M2020377).

Informed Consent Statement: Not applicable.

Data Availability Statement: The data presented in this study are available on request from the first/corresponding author. The data are not publicly available due to confidentiality agreement with Peking University Third Hospital.

Conflicts of Interest: The authors declare no conflict of interest.

\section{References}

1. Levine, D.P. Vancomycin: A history. Clin. Infect. Dis. 2006, 42, S5-S12. [CrossRef]

2. Geraci, J.E.; Heilman, F.R.; Nichols, D.R.; Ross, G.T.; Wellman, W.E. Some laboratory and clinical experiences with a new antibiotic, vancomycin. Proc. Staff Meet. Mayo Clin. 1956, 31, 564-582. [PubMed]

3. Spadaro, S.; Berselli, A.; Fogagnolo, A.; Capuzzo, M.; Ragazzi, R.; Marangoni, E.; Bertacchini, S.; Volta, C.A. Evaluation of a protocol for vancomycin administration in critically patients with and without kidney dysfunction. BMC Anesth. 2015, 15, 95. [CrossRef] [PubMed]

4. He, J.; Yang, Z.T.; Qian, X.; Zhao, B.; Mao, E.Q.; Chen, E.Z.; Bian, X.L. A higher dose of vancomycin is needed in critically ill patients with augmented renal clearance. Transl. Androl. Urol. 2020, 9, 2166-2171. [CrossRef] [PubMed]

5. Liu, N.; Zhang, B.; Liu, Y.; Tang, J.; Dong, D.; Gu, Q. Clinical study of vancomycin for appropriate dosing in severe infective patients with augmented renal clearance. Zhonghua Wei Zhong Bing Ji Jiu Yi Xue 2018, 30, 646-651. [CrossRef]

6. He, C.Y.; Qin, Y.R.; Liu, C.J.; Ren, J.; Fan, J.S. Effect of augmented renal clearance on plasma concentration of vancomycin and treatment outcome in children with methicillin-resistant Staphylococcus aureus infection. Zhongguo Dang Dai Er Ke Za Zhi 2019, 21, 904-909. [PubMed]

7. Lodise, T.P.; Drusano, G.L.; Zasowski, E.; Dihmess, A.; Lazariu, V.; Cosler, L.; McNutt, L.A. Vancomycin exposure in patients with methicillin-resistant Staphylococcus aureus bloodstream infections: How much is enough? Clin. Infect. Dis. 2014, 59, 666-675. [CrossRef]

8. Claus, B.O.; Hoste, E.A.; Colpaert, K.; Robays, H.; Decruyenaere, J.; De Waele, J.J. Augmented renal clearance is a common finding with worse clinical outcome in critically ill patients receiving antimicrobial therapy. J. Crit. Care 2013, 28, 695-700. [CrossRef]

9. Liu, T.T.; Pang, H.M.; Jing, L.; Wei, W.X.; Qin, X.L.; Guo, Q.; Lu, H.; Cheng, D.H.; Jiang, W.Z. A population pharmacokinetic model of vancomycin for dose individualization based on serum cystatin $\mathrm{C}$ as a marker of renal function. J. Pharm. Pharmacol. 2019, 71, 945-955. [CrossRef]

10. Pitaksontayothin, K.; Santimaleeworagun, W.; Pongchaidecha, M.; Houngsaitong, J.; Srisena, P. The use of monte carlo simulation to predict vancomycin dosage for methicillin-resistant staphylococcus aureus in Thai patients of various ages and with varying degrees of renal function. Asian Biomed. 2017, 11, 379-385. [CrossRef]

11. Deng, C.; Liu, T.; Zhou, T.; Lu, H.; Cheng, D.; Zhong, X.; Lu, W. Initial dosage regimens of vancomycin for Chinese adult patients based on population pharmacokinetic analysis. Int. J. Clin. Pharmacol. Ther. 2013, 51, 407-415. [CrossRef] [PubMed] 
12. Thomson, A.H.; Staatz, C.E.; Tobin, C.M.; Gall, M.; Lovering, A.M. Development and evaluation of vancomycin dosage guidelines designed to achieve new target concentrations. J. Antimicrob. Chemother. 2009, 63, 1050-1057. [CrossRef] [PubMed]

13. Dolton, M.; Xu, H.; Cheong, E.; Maitz, P.; Kennedy, P.; Gottlieb, T.; Buono, E.; McLachlan, A.J. Vancomycin pharmacokinetics in patients with severe burn injuries. Burns 2010, 36, 469-476. [CrossRef]

14. Sanchez, J.L.; Dominguez, A.R.; Lane, J.R.; Anderson, P.O.; Capparelli, E.V.; Cornejo-Bravo, J.M. Population pharmacokinetics of vancomycin in adult and geriatric patients: Comparison of eleven approaches. Int. J. Clin. Pharmacol. Ther. 2010, 48, 525-533. [CrossRef] [PubMed]

15. Tanaka, A.; Aiba, T.; Otsuka, T.; Suemaru, K.; Nishimiya, T.; Inoue, T.; Murase, M.; Kurosaki, Y.; Araki, H. Population pharmacokinetic analysis of vancomycin using serum cystatin $\mathrm{C}$ as a marker of renal function. Antimicrob. Agents Chemother. 2010, 54, 778-782. [CrossRef]

16. Chu, Y.; Luo, Y.; Qu, L.; Zhao, C.; Jiang, M. Application of vancomycin in patients with varying renal function, especially those with augmented renal clearance. Pharm. Biol. 2016, 54, 2802-2806. [CrossRef]

17. Monteiro, J.F.; Hahn, S.R.; Goncalves, J.; Fresco, P. Vancomycin therapeutic drug monitoring and population pharmacokinetic models in special patient subpopulations. Pharmacol. Res. Perspect. 2018, 6, e420. [CrossRef]

18. Chen, Y.; Liu, L.; Zhu, M. Effect of augmented renal clearance on the therapeutic drug monitoring of vancomycin in patients after neurosurgery. J. Int. Med. Res. 2020, 48, 1220748628. [CrossRef]

19. He, J.; Mao, E.; Jing, F.; Jiang, H.; Xu, W.; Yang, W.; Chen, E. PK/PD of vancomycin in patients with severe acute pancreatitis combined with augmented renal clearance. Zhonghua Wei Zhong Bing Ji Jiu Yi Xue 2017, 29, 810-814. [CrossRef]

20. Chu, Y.; Luo, Y.; Ji, S.; Jiang, M.; Zhou, B. Population pharmacokinetics of vancomycin in Chinese patients with augmented renal clearance. J. Infect. Public Health 2020, 13, 68-74. [CrossRef]

21. Roberts, J.A.; Taccone, F.S.; Udy, A.A.; Vincent, J.L.; Jacobs, F.; Lipman, J. Vancomycin dosing in critically ill patients: Robust methods for improved continuous-infusion regimens. Antimicrob. Agents Chemother. 2011, 55, 2704-2709. [CrossRef]

22. Del, M.F.D.G.; Revilla, N.; Calvo, M.V.; Dominguez-Gil, A.; Sanchez, N.A. Pharmacokinetic/pharmacodynamic analysis of vancomycin in ICU patients. Intensive Care Med. 2007, 33, 279-285. [CrossRef]

23. Llopis-Salvia, P.; Jimenez-Torres, N.V. Population pharmacokinetic parameters of vancomycin in critically ill patients. J. Clin. Pharm. Ther. 2006, 31, 447-454. [CrossRef] [PubMed]

24. Niederman, M.S.; Baron, R.M.; Bouadma, L.; Calandra, T.; Daneman, N.; DeWaele, J.; Kollef, M.H.; Lipman, J.; Nair, G.B. Initial antimicrobial management of sepsis. Crit. Care 2021, 25, 307. [CrossRef] [PubMed]

25. Povoa, P.; Moniz, P.; Pereira, J.G.; Coelho, L. Optimizing Antimicrobial Drug Dosing in Critically Ill Patients. Microorganisms 2021, 9, 1401. [CrossRef] [PubMed]

26. De Paepe, P.; Belpaire, F.M.; Buylaert, W.A. Pharmacokinetic and pharmacodynamic considerations when treating patients with sepsis and septic shock. Clin. Pharmacokinet. 2002, 41, 1135-1151. [CrossRef] [PubMed]

27. Guilhaumou, R.; Benaboud, S.; Bennis, Y.; Dahyot-Fizelier, C.; Dailly, E.; Gandia, P.; Goutelle, S.; Lefeuvre, S.; Mongardon, N.; Roger, C.; et al. Optimization of the treatment with beta-lactam antibiotics in critically ill patients-guidelines from the French Society of Pharmacology and Therapeutics (Societe Francaise de Pharmacologie et Therapeutique-SFPT) and the French Society of Anaesthesia and Intensive Care Medicine (Societe Francaise d'Anesthesie et Reanimation-SFAR). Crit. Care 2019, $23,104$. [CrossRef] [PubMed]

28. De Backer, D.; Cecconi, M.; Lipman, J.; Machado, F.; Myatra, S.N.; Ostermann, M.; Perner, A.; Teboul, J.L.; Vincent, J.L.; Walley, K.R. Challenges in the management of septic shock: A narrative review. Intensive Care Med. 2019, 45, 420-433. [CrossRef]

29. Roberts, J.A.; Abdul-Aziz, M.H.; Lipman, J.; Mouton, J.W.; Vinks, A.A.; Felton, T.W.; Hope, W.W.; Farkas, A.; Neely, M.N.; Schentag, J.J.; et al. Individualised antibiotic dosing for patients who are critically ill: Challenges and potential solutions. Lancet Infect. Dis. 2014, 14, 498-509. [CrossRef]

30. Okada, A.; Kariya, M.; Irie, K.; Okada, Y.; Hiramoto, N.; Hashimoto, H.; Kajioka, R.; Maruyama, C.; Kasai, H.; Hamori, M.; et al. Population Pharmacokinetics of Vancomycin in Patients Undergoing Allogeneic Hematopoietic Stem-Cell Transplantation. J. Clin. Pharmacol. 2018, 58, 1140-1149. [CrossRef]

31. Finch, N.A.; Zasowski, E.J.; Murray, K.P.; Mynatt, R.P.; Zhao, J.J.; Yost, R.; Pogue, J.M.; Rybak, M.J. A Quasi-Experiment To Study the Impact of Vancomycin Area under the Concentration-Time Curve-Guided Dosing on Vancomycin-Associated Nephrotoxicity. Antimicrob. Agents Chemother. 2017, 61, e01293-17. [CrossRef]

32. Rybak, M.J.; Le, J.; Lodise, T.; Levine, D.; Bradley, J.; Liu, C.; Mueller, B.; Pai, M.; Wong-Beringer, A.; Rotschafer, J.C.; et al. Executive Summary: Therapeutic Monitoring of Vancomycin for Serious Methicillin-Resistant Staphylococcus aureus Infections: A Revised Consensus Guideline and Review of the American Society of Health-System Pharmacists, the Infectious Diseases Society of America, the Pediatric Infectious Diseases Society, and the Society of Infectious Diseases Pharmacists. J. Pediatr. Infect. Dis. Soc. 2020, 9, 281-284. [CrossRef] [PubMed]

33. Men, P.; Li, H.B.; Zhai, S.D.; Zhao, R.S. Association between the AUC0-24/MIC Ratio of Vancomycin and Its Clinical Effectiveness: A Systematic Review and Meta-Analysis. PLoS ONE 2016, 11, e146224. [CrossRef] [PubMed] 
34. Aljefri, D.M.; Avedissian, S.N.; Rhodes, N.J.; Postelnick, M.J.; Nguyen, K.; Scheetz, M.H. Vancomycin Area Under the Curve and Acute Kidney Injury: A Meta-analysis. Clin. Infect. Dis. 2019, 69, 1881-1887. [CrossRef] [PubMed]

35. He, N.; Su, S.; Ye, Z.; Du, G.; He, B.; Li, D.; Liu, Y.; Yang, K.; Zhang, X.; Zhang, Y.; et al. Evidence-based Guideline for Therapeutic Drug Monitoring of Vancomycin: 2020 Update by the Division of Therapeutic Drug Monitoring, Chinese Pharmacological Society. Clin. Infect. Dis. 2020, 71, S363-S371. [CrossRef] 